\title{
Influence of Twisting Degree and Number of Cords on the Structure of Silk
}

\author{
Dilfuza Khudayberdieva, Nodira Amirova, Mavjuda Abdukarimova, S. Khazova, \\ Nargiz Mirzahmedova
}

Tashkent Institute of Textile and Light Industry, Tashkent, Uzbekistan.

E-mail: niroda@rambler.ru

Received February 21 ${ }^{\text {st }}, 2011$; revised April 1 $1^{\text {st }}, 2011$; accepted April $29^{\text {th }}, 2011$.

\begin{abstract}
Properties of the fibrous material which has oriented supermolecular formations are depended on such structural factors as morphology, inter position of structure elements, and their interaction. Influence of processing on changing original structure of fibrous material during mechanical processing that causes deformation at loading is determined by peculiarities of its structure. Reversible and irreversible changes of structural elements in fibrous material causes changing of volume and sorption properties and will essentially influence on its chemical finishing processes. Influence of twisting degree and number of silk cords on structure and physical mechanical properties. Changing of supermolecular structure of thread in the process of its forming by X-ray graphic, sorption and focused beam electronic microscopic methods was researched.
\end{abstract}

Keywords: Twisting, Cord of Threads, Degree of Crystallinity, Volume Properties

\section{Introduction}

In mechanical technology at rewinding, twisting and weaving silk threads are subjected to deformation which finally causes reconstruction of not only separate filaments in threads but also of structural elements in amorphous and crystalline parts of supermolecular silk structure.

The analysis of a priori and periodic literary sources has shown that mainly the influence of twist and linear density of crape threads on mechanical and working properties of crape fabrics were researched. The author of the work [1] researched physical-mechanical and working properties of crape threads samples with different linear density, twisting and number of cords. Changing the quantity of cords in crape threads with twist $2200 \mathrm{tw} / \mathrm{m}$ causes increasing of breaking load of the fabric, durability of angle fastening in the fabric, rubbing resistance and fabric capillarity, as filling of the fabric and its thickness increase. Increasing twists up to $3200 \mathrm{tw} / \mathrm{m}$ causes significant decrease of rubbing resistance of the fabric, and breaking load and durability of threads fastening in fabrics change very little.

Using natural silk for making knitted goods, the influence of cord and twist number on physical and mechaniccal properties of silk threads were investigated in the work [2].
Increasing of twist up to $500 \mathrm{tw} / \mathrm{m}$ breaking load increases, the same conformity with law can be seen in changing cord of threads. These results are connected with the changes that take place in the structure of silk threads by the influence of mechanical forces in twisting.

$\mathrm{H}$. Ito researched the influence of silkworm diet in aseptic conditions on silk composition and its properties. X-ray diffraction pattern and dyeing properties of the an artificial diet fibroin were nearly the same as those of the mulberry leaf diet fibroin. The artificial diet used in this study affects the structure and properties of sericin proteins, and a little those of fibroin proteins [3].

The works of scientists from Slovenia [4-6], both experimental and theoretical, are devoted to researching the quality of coloring and reproduction the color depending on fabrics structure.

Indian scientists [7] investigated the amino acid composition of five types of silk fibers obtained by feeding silkworms with mulberry leaves of two types and three types of other plants. The content of various amino acids in the fiber obtained from the inner and outer layers of the cocoon was compared. Difference between structure and properties of silk fibers was determined. Strength and density of the filaments by birefringence method were researched. Coloring different types of fibers by acid dyes is correlated with the content of terminal amino 
groups in polymer molecules of silk.

In the process of mechanical technology under the influence of tension in fibrous materials changes of fibre surface and structure take place, they lead to the changes of cristallinity index [8].

Knitted goods made of cotton yarn with different type of spinning, yarn counts, twist factors and structures have various physical and mechanical quality indexes $[9,10]$.

In literary sources there is no information about influencing the conditions of processes in mechanical technology of textile materials on structural transformations of fibers on supermolecular level and influencing these changes on silk coloring.

\section{Materials and Methods}

The subjects of the research were: silk threads with different twist and different number of cords (n): 1-Thread for han-atlas fabrics - total twisting $338 \mathrm{tw} / \mathrm{m}$, linear density 3.22 tex; $\mathrm{n}=2.3$ direction of twist $\mathrm{S}$; 2-Thread for shirt fabric - total twisting $700 \mathrm{tw} / \mathrm{m}$, linear density 3.22 tex; $\mathrm{n}=2.6$ threads, direction of twist $\mathrm{S}$; 3-Crape thread - total twisting $2000 \mathrm{tw} / \mathrm{m}$, linear density 3.22 tex; $\mathrm{n}=2.4$ of thread, direction of twist $\mathrm{S}$.

Twist was made on Composite Winder Type MT-CWD/T machine. Conformance of obtained and set twists was determined on Twist Counter device. The obtained twist was fixed in steam medium within $10-20$ minutes depending on thickness of winding threads on a bobbin in autoclave.

Physical and mechanical properties of threads were researched in an accredited educational-certification center "CentexUZ" in TITLI on AUTOGRAPH AG-1 devices.

The sorption of water steams was investigated with the help of Mc Ben spring tungsten scales with sensitivity $1.5 \mathrm{mg} / \mathrm{mm}$ at $25^{\circ} \mathrm{C} \pm 0.1^{\circ} \mathrm{C}$ and residual pressure $10-5$ $\mathrm{mm}$. Hg. 5 parallel determinations were made. Relative mistake in measurement was $1.5 \%$. The evaluation of magnitude pores radiuses, $\AA$, was made according to the method [11].

According to isotherms of sorption magnitude of specific surface was defined- $\mathrm{S}_{\mathrm{sp}}$, of silk. $\mathrm{S}_{\mathrm{sp}}-$ of the silk was calculated according to Brunauer-Emmet-Teller (BET) equation according to the method.

Total volume of pores was calculated according to formulae:

$\mathrm{W}_{0}=\mathrm{a} / \rho ;$ where,

$\mathrm{a}$-adsorbent mass taken at impregnation $\mathrm{P} / \mathrm{P}_{0}=1$

$\rho$-adsorbent density

Average radius of capillaries was calculated from the ratio

$\mathrm{r}_{\mathrm{n}}=2 \cdot \mathrm{W}_{0} \cdot 10^{-4} / \mathrm{S}_{\mathrm{sp}}[11]$

Radiographic investigation of the samples was made on X-ray diffractometer "DRON-3H" with monochro- matized $\mathrm{Cu} \mathrm{K}_{\alpha}$-radiation at tension $22 \mathrm{kV}$ and current power $12 \mathrm{~mA}$ which were chosen depending on the preparation. The samples were made by pressing pounded preparations in the form of tablets. The survey was made in the interval of $2 \theta=10^{\circ}-35^{\circ}$. Crystallinit degrees $(\mathrm{Dc})$ were determined according to GermanVeidinger method. The evaluation of crystallinity degrees was made according to the ratio of peak intensity for one of the main maximums the altitude of which was proportional to crystallinity degrees, to so-called amorphous dispersal.

$$
\operatorname{Dc}(\%)=\frac{(\mathrm{I} \kappa-\mathrm{I} a)}{\mathrm{I} \kappa} \times 100 \%
$$

where, I $\kappa$ and $\mathrm{I} a$-intensity of crystal reflex and amorphous dispersal, accordingly [12].

The research was made on focused beam electronic microscope REM-250. In order to exclude the electric charge which is sharply accumulated on non-conducting sample in scanning, the samples were covered with a thin film. For this, the sample was placed in high-vacuum evaporator VEP-4K and was covered with silver.

\section{Experiment}

In initial stage of the research physical and mechanical properties of silk textile thread with different twist degree and cord of threads were investigated (Table 1).

With increasing of twist, the durability of the thread increases to some critical point, then strength properties decrease. Increasing of elementary threads in textile thread causes increasing of its durability.

For revealing changes in supermolecular structure volume and superficial properties of threads with different twist and number of threads cords using sorption, $\mathrm{X}$-ray methods were researched, and external surface of the samples was researched by focused beam electronic microscopy.

REM-researching of the Silk samples showed the following results: initial untwisted natural silk thread has a smooth surface (Figure 1), here and there slightly coarse with rare linear thin folds along the fiber axis.

Table 1. Physical and mechanical properties of silk textile threads with different degree of twist and cord of threads.

\begin{tabular}{cccccc}
\hline $\begin{array}{c}\text { Samples of } \\
\text { threads for fabric }\end{array}$ & $\begin{array}{c}\text { Twist } \\
\text { tw/m }\end{array}$ & $\begin{array}{c}\text { Number } \\
\text { of } \\
\text { cords, n }\end{array}$ & $\begin{array}{c}\text { Linear } \\
\text { density } \\
\mathrm{N}, \text { tex }\end{array}$ & $\begin{array}{c}\text { Breaking } \\
\text { load, } \\
\mathrm{P}_{\mathrm{p}}, \mathrm{cH}\end{array}$ & $\begin{array}{c}\text { Elongation } \\
\text { at break L, } \\
\%\end{array}$ \\
\hline "Han-atlas" & 338 & 2 & 5.14 & 122.91 & 8.33 \\
"Shirt" & 700 & 2 & 5.0 & 204.84 & 17.41 \\
& 700 & 6 & 17.0 & 502.73 & 19.41 \\
& 2000 & 2 & 5.5 & 144.91 & 14.82 \\
\hline
\end{tabular}




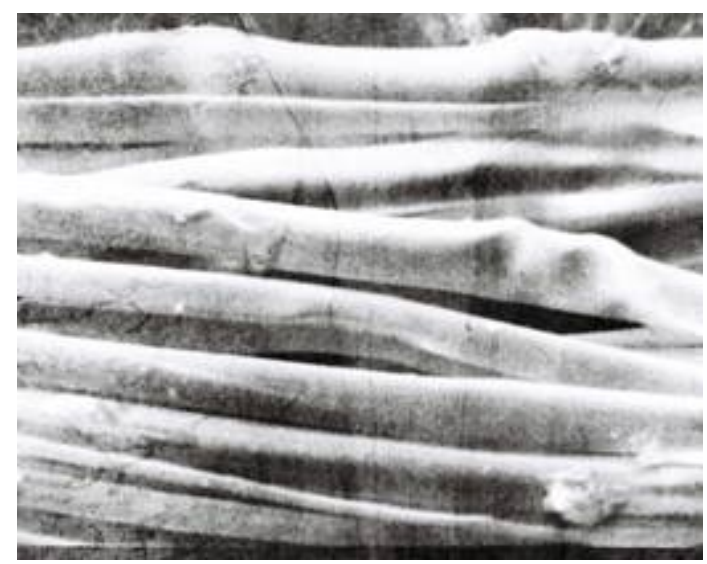

(a)

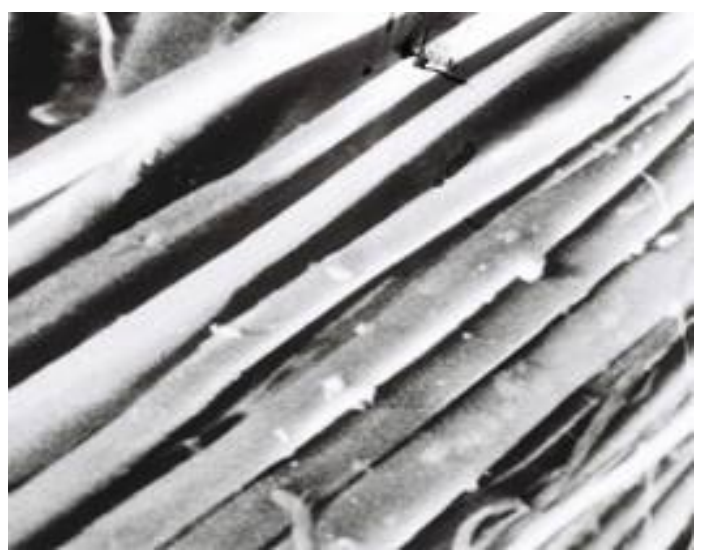

(c)

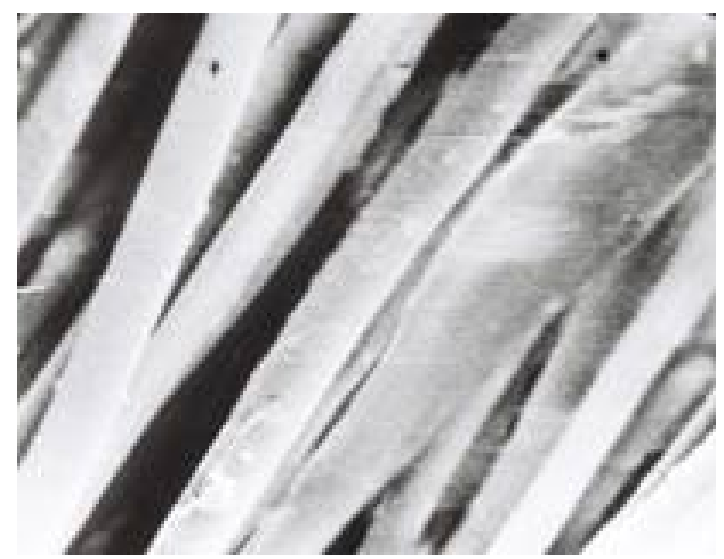

(b)

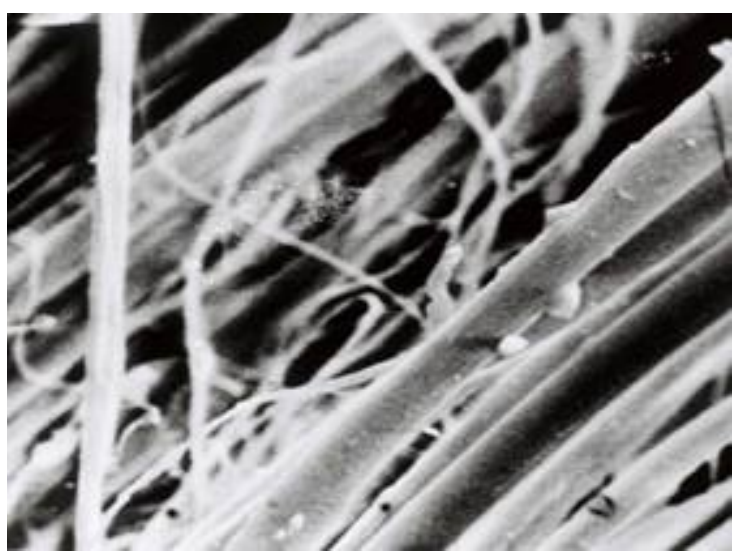

(d)

Figure 1. REM surveys of samples with different twist: (a) untwisted; twisted x; (b) With twist 338 tw/m; (c) With twist 700 tw/m; (d) With twist 2000 tw/m silk thread.

The silk thread which has twist $338 \mathrm{tw} / \mathrm{m} \times 2$ differs very little (Figures 1(a) and (b).) from initial silk by surface structure, but when twist increases $(700 \mathrm{tw} / \mathrm{m} \times 2)$ micro- and macro-defects appear on the surface (Figures 1(c) and (d)). Significant superficial change takes place at high twisting of textile thread. For the fabric of crape assortment $(2000 \mathrm{tw} / \mathrm{m} \times 2)$ twist can be seen clearly, practically we can't see fibril elements (Figure 1(d)). When twist increases we can see significant superficial change and also micro- and macro-defects, twistedness, bends, breaks, elementary fibre fibrilization. Changing of thread surface, appearing of cracks and fractures undoubtedly influence on volume properties of the threads. In connection with this sorption and volume properties of natural silk threads samples with different twist and cord were researched (Table 2).

According to the results of researching sorption properties it was determined that in the result of twisting compared with initial untwisted silk all the samples of silk threads for corresponding fabrics with different cord of threads indexes of specific surface decreasing $-S_{\mathrm{sp}}$, and at the same time radius of pores $-r_{\Pi}$ of the fiber increases. Changing of pores total volume- $-\mathrm{W}_{0}, \mathrm{~S}_{\mathrm{sp}}$ and $\mathrm{r}_{\mathrm{n}}$ differs depending on the number of cords of threads. At the same number of filaments $\mathrm{W}_{0}$ and $\mathrm{r}_{\mathrm{n}}$ fibers increase $(338 \mathrm{tw} / \mathrm{m})$, then sharply decrease. $\mathrm{S}_{\mathrm{sp}}$ at twisting degree of $338 \mathrm{tw} / \mathrm{m}$ decreases compared wilh initial silk, then at 700 and $2000 \mathrm{tw} / \mathrm{m}$ it increases again. If number of cords and twist degree are different at changing from $338 \mathrm{tw} / \mathrm{m}$ to 700 and $2000 \mathrm{tw} / \mathrm{m} \mathrm{S}_{\mathrm{sp}}, \mathrm{W}_{0}$ decrease, and $\mathrm{r}_{\mathrm{n}}$ for threads $700 \mathrm{tw} / \mathrm{m}$ in 6 cords - is the largest.

Crystallinity degree of textile thread for defining structural changes in result of twisting was evaluated.

Comparing crtystallinity degree for the samples obtained by combining in two threads with different number of twist its $C_{d}$ decreases when number of twist increases. However, intensive twist with large number of threads causes increasing of crystallinity degree signifycantly (Table 3).

\section{Results and Discussion}

Density of packaging structural elements is one of the 
Table 2. Water stems sorption by silk samples at $25^{\circ} \mathrm{C}$.

\begin{tabular}{|c|c|c|c|c|c|c|}
\hline \multirow{2}{*}{$\begin{array}{l}\text { Relative wetness of water } \\
\text { steams, } \%\end{array}$} & \multicolumn{6}{|c|}{ Water stems sorption in \% by threads will different cards number } \\
\hline & initial & $3.23 \times 2 \mathrm{~S} 338$ & $3.23 \times 2 \mathrm{~S} 700$ & $3.23 \times 2 \mathrm{~S} 2000$ & $3.23 \times 6 \mathrm{~S} 700$ & $3.23 \times 4 \mathrm{~S} 2000$ \\
\hline 10 & 1.1 & 1.0 & 1.2 & 1.0 & 0.5 & 0.7 \\
\hline 30 & 2.5 & 2.3 & 2.9 & 2.4 & 1.1 & 1.6 \\
\hline 50 & 3.3 & 3.1 & 4.0 & 3.3 & 1.7 & 2.4 \\
\hline 65 & 4.2 & 3.7 & 5.1 & 3.9 & 2.6 & 3.3 \\
\hline 80 & 6.0 & 4.9 & 6.4 & 4.8 & 4.9 & 4.5 \\
\hline 90 & 7.8 & 6.40 & 7.5 & 5.6 & 5.0 & 5.9 \\
\hline 100 & 10.8 & 13.9 & 10.5 & 7.5 & 7.6 & 8.5 \\
\hline
\end{tabular}

Table 3. Superficial and volume properties of silk threads.

\begin{tabular}{|c|c|c|c|c|c|c|}
\hline $\begin{array}{l}\text { Sample of thread for } \\
\text { fabric }\end{array}$ & $\begin{array}{l}\text { Twist, } \\
\text { tw/m }\end{array}$ & $\begin{array}{l}\text { Number of cords, } \\
n\end{array}$ & $\begin{array}{l}\text { Specific surfac } \\
\left(\mathrm{S}_{\mathrm{su}}, \mathrm{M}^{2} / \mathrm{gr}\right)\end{array}$ & $\begin{array}{c}\text { Total volume of } \\
\text { pores }\left(\mathrm{W}_{\mathrm{p}}, \mathrm{sm}^{3} / \mathrm{gr}\right)\end{array}$ & $\begin{array}{l}\text { Radius of pores } \\
\qquad\left(\mathrm{r}_{\mathrm{p}}, \AA\right)\end{array}$ & $\begin{array}{c}\text { Crystal linity } \\
\text { degree, } \%\end{array}$ \\
\hline $\begin{array}{l}\text { Initial untwisted } \\
\text { thread }\end{array}$ & 0 & 1 & 83.712 & 0.108 & 25.8 & 62.0 \\
\hline "Han-atlas" & 338 & 2 & 78.177 & 0.139 & 35.56 & 64.0 \\
\hline \multirow{2}{*}{ "Shirt" } & 700 & 2 & 84.763 & 0.075 & 17.7 & 61.0 \\
\hline & 700 & 6 & 36.034 & 0.076 & 42.18 & 67.0 \\
\hline \multirow{2}{*}{ "Crepe-de-chine" } & 2000 & 2 & 102.990 & 0.109 & 21.1 & 58.7 \\
\hline & 2000 & 4 & 54.093 & 0.085 & 25.8 & 68.8 \\
\hline
\end{tabular}

most important physical characteristics which stipulate the complex of structural-mechanical and sorption properties of fiber material.

Extreme nature of dependence of textile threads twist and durability can be explained by increasing friction forces between fibers at twisting to the values that exceed fibers durability. At further of increasing yarn twistedness breaking of fibers increases because of twisting deformation and pressing and in the result yarn durability decreases [13].

Textile thread must have system of submicroscopic pores that form developed inner surface with active centers which provide diffusion and fixation of the dye during coloring. Effective free volume can change in the processing and chemical finishing of the fiber.

In initial silk undense packing of structural elements may take place because of steric obstacles of big side substitutes and also in the result of thermal motion of macromolecules.

Emptinesses that appear are approximately equal to the volume of statistic polypeptide segment cause undensity of packing in amorphous parts. The larger emptinesses and pores in the fiber are determined by the peculiarities of packing different fibrillar structures on all levels of supermolecular formations of fibroin [14]. These correlations obviously change in the process of deformation, decrease or increase depended to loading regime. The changes are the result of the action of several opposite factors which cause:

- Increasing or decreasing of pores sizes, that promote to appearance of micro and macro defects by the influence of tension in the process of twist;

- Crystallity degree and regulation of fibroin macromoleciles, that promote to increasing intensity of intermolecular interaction.

These facts allow to make the conclusion that the changes in supermolecular structure of twisted silk threads must influence on kinetic and thermodynamic characteristics in dyeing process.

On the basis of these data the influence of these changes on the quality of dyeing was researched. For dyeing active vinylsulfon dyes Ostacolor Ostazin VR blue and yellow Ostazin VGR were used. The kinetics of dyeing threds samples with different twist, at $65^{\circ} \mathrm{C}, 75^{\circ} \mathrm{C}, 85^{\circ} \mathrm{C}$ (Table 4) was investigated.

Determining the quantity of adsorbed and fixed dye on 
the fiber in identical conditions of dyeing for all the samples showed that the filament "Han-atlas" $338 \mathrm{kr} / \mathrm{m}$ $\times 2$ absorbs more dye than "Shirt" and "Crepe-dechine" of the same cord. Sorption of "Crepe-de-chine" thread $(2000 \mathrm{tw} / \mathrm{m} \times 4)$ is less than of "Shirt" $(700 \mathrm{tw} / \mathrm{m}$ $\times 6)$ ones. The same effect can be seen at fixation of the dye on the threads. Twist degree of threads doesn't influence significantly on the dye sorption, but the fixation of the dye doubles with increasing degree of threads twist. On the basis of kinetic curves values of diffusion coefficients in dyeing process (Tables 5 and 6 ) were calculated.

Threads for "Han-atlas" have pores with a large radius and total pore volume, therefore the dye diffuses into the fiber easier. The values of the diffusion coefficient of dyeing "Han-atlas" threads are higher compared with other samples. When temperature increase the diffusion coefficient of dyeing Ostazin blue VR increases, then it decreases a little, while the Ostazin yellow VGR uniformly increases. Differences between changes in diffusion coefficient and the type of dye are probably connected with the structure of the molecule.

\section{Conclusions}

With increasing of twist thread durability of increases to some critical value and causes significant surface changes.

In the result of twisting $S_{\mathrm{sp}}$ increases and at the same time $r_{n}$ of the fiber decreases. Conformity to some established law of $S_{s p}$ and $r_{n}$ changes to some extent differs depending on the number of threads cords At high twist degree of $(2000 \mathrm{tw} / \mathrm{m}) \mathrm{S}_{\mathrm{sp}}, \mathrm{W}_{0}$ decrease and $\mathrm{r}_{\mathrm{n}}$ for threads changes little.

Table 4. Influence of dyeing temperature on the equilibrium sorption and fixation of the dye by silk threads with different twist degree and with the cord of 2 threads.

\begin{tabular}{|c|c|c|c|c|c|c|c|c|c|c|c|c|}
\hline \multirow{3}{*}{ Temperature, ${ }^{\circ} \mathrm{C}$} & \multicolumn{6}{|c|}{ Ostazin blue VR } & \multicolumn{6}{|c|}{ Ostazin yellow VGR } \\
\hline & \multicolumn{2}{|c|}{$338 \mathrm{tw} / \mathrm{m}$} & \multicolumn{2}{|c|}{$700 \mathrm{tw} / \mathrm{m}$} & \multicolumn{2}{|c|}{$2000 \mathrm{tw} / \mathrm{m}$} & \multicolumn{2}{|c|}{$338 \mathrm{tw} / \mathrm{m}$} & \multicolumn{2}{|c|}{$700 \mathrm{tw} / \mathrm{m}$} & \multicolumn{2}{|c|}{$2000 \mathrm{tw} / \mathrm{m}$} \\
\hline & $\mathrm{C}^{*}$ & $\mathrm{C}^{* *}$ & $\mathrm{C}^{*}$ & $\mathrm{C}^{* *}$ & $\mathrm{C}^{*}$ & $\mathrm{C}^{* *}$ & $\mathrm{C}^{*}$ & $\mathrm{C}^{* *}$ & $\mathrm{C}^{*}$ & $\mathrm{C}^{* *}$ & $\mathrm{C}^{*}$ & $\mathrm{C}^{* *}$ \\
\hline 45 & 17.0 & 12.9 & 16.4 & 12.6 & 14.1 & 10.2 & 13.6 & 10.5 & 13.5 & 9.9 & 12.4 & 8.95 \\
\hline 65 & 17.9 & 14.4 & 17.8 & 14.05 & 17.8 & 14.0 & 15.8 & 13.5 & 15.4 & 13.4 & 15.2 & 13.2 \\
\hline 85 & 16.0 & 10.6 & 14.5 & 8.6 & 12.5 & 7.0 & 13.6 & 10.8 & 13.1 & 10.8 & 13.0 & 10.2 \\
\hline
\end{tabular}

$\mathrm{C}^{*}$ amount of sorbed dye gr $/ \mathrm{kg}, \mathrm{C}^{* *}$ of dye fixation $\mathrm{gr} / \mathrm{kg}$.

Table 5. Influence on equilibrium sorption and fixation of the dye by silk threads with different twist, and with cord of threads.

\begin{tabular}{ccccc}
\hline \multirow{2}{*}{$\begin{array}{c}\text { Thread sample with twist (tw/m) and the } \\
\text { number of cords }\end{array}$} & \multicolumn{2}{c}{ Ostazin blue VR } & \multicolumn{2}{c}{ Ostazin yellow VGR } \\
\cline { 2 - 5 } & $\mathrm{C}^{*}$ & $\mathrm{C}^{* *}$ & $\mathrm{C}$ & $\mathrm{C}$ \\
\hline $338 \times 2$ & 16.65 & 4.95 & 16.6 & 4.1 \\
$700 \times 6$ & 15.85 & 5.85 & 15.2 & 5.2 \\
$2000 \times 4$ & 15.55 & 8.05 & 13.75 & 8.75 \\
\hline
\end{tabular}

Table 6. Dependence of diffusion coefficient $D \cdot 10^{12} \mathrm{~m}^{2} / \mathrm{sec}$ on twist degree and temperature of dyeing.

\begin{tabular}{|c|c|c|c|c|c|c|c|c|}
\hline \multirow{2}{*}{ Samples of threads for fabric } & \multirow{2}{*}{ Twist, tw/m } & \multirow{2}{*}{$\begin{array}{l}\text { Number of } \\
\text { cords, } \mathrm{n}\end{array}$} & \multicolumn{3}{|c|}{ Ostazin blue VR } & \multicolumn{3}{|c|}{ Ostazin yellow VGR } \\
\hline & & & $45^{\circ} \mathrm{C}$ & $65^{\circ} \mathrm{C}$ & $85^{\circ} \mathrm{C}$ & $45^{\circ} \mathrm{C}$ & $65^{\circ} \mathrm{C}$ & $85^{\circ} \mathrm{C}$ \\
\hline "Han-atlas" & 338 & 2 & 16.8 & 19.0 & 18.0 & 12.2 & 12.5 & 14.0 \\
\hline "Shirt" & 700 & 6 & 14.0 & 16.1 & 14.0 & 11.0 & 10.0 & 13.3 \\
\hline "Crepe-de-chine" & 2000 & 4 & 13.0 & 15.0 & 12.0 & 8.3 & 9.8 & 11.7 \\
\hline
\end{tabular}


Crystallinity degree of the thread with increasing twist at identical number of cords decreases. However intensive twist with large number of threads cord causes increasing of crystallinity degree, that makes difficult dye diffusion inside the fibre.

\section{REFERENCES}

[1] M. Ya. Mustafaeva, "Influence of Twisting and Linear Density of Crape Threads on the Properties of "Crepede-Chine' Fabrics. Silk,” Tashkent 1984, No. 1, 1984, pp. 24-26.

[2] H. Alimova, "Non-Waste Less Technology of Silk Processing," Tashkent Science Publishing House, Tashkent, 1994, p. 309.

[3] H. Ito, T. Imamura, K. Uemura, M. Yoshida, H. Sasaki and N. Donkai, "New Diet, New Silk," Textile Asia, Vol. 32, No. 10, 2000, pp. 26-29

[4] K. Dimitrovski, S. Jeler and M. KumarBarvno, "Oblikovanje Pestrih Tkanin. Interdisciplinalmost Barve-2.det, Maribor," Drustvo Koloristov Slovenije, Vol. 8, 2004, pp 455-475.

[5] T. N. Kocevar, "Optic no Mesanje barv na PovrSini Tkanine. Interdisciplinamost Barve-2.det, Interdisciplinalmost Barve-2.det, Maribor," Drustvo koloristov Slovenije, Vol. 8, 2004, pp. 195-210.

[6] H. Gabrijelcic and K. Dimitrovski, "Influence of Yarn and Weft Thread Density on Color Values Woven Surfaces," Fibres \& Textiles in Eastern Europe, Vol. 12, 2004, pp. 32-39
[7] B. M. K. Kushal, "Structure on Silk Indian Silk. IMacroharoc-Terization and Ahalysis of Amino Acid Composition; II-Structure-Property Correlations; IIIEffect on Dyeing Behavior," Journal of Applied Polymer Science, Vol. 92, 2004, pp. 1080-1123

[8] D. S. Dai, "Mizi Fan Characteristic and Performance of Elementary Hemp Fibre," Materials Sciences and Applications, Vol. 1, No. 6, 2010, pp. 336-342.

[9] K. S. Dönmez, A. T. Özgüney, G. Özçelik and A. Özerdem, "The Comparison of Cotton Knitted Fabric Properties Made of Compact and Conventional Ring Yarns before and after the Dyeing Process," Textile Research Journal, Vol. 77, No. 4, 2007, pp. 233-241. doi: $10.1177 / 0040517507076745$

[10] C. D. Kane, U. J. Patil and P. Sudhakar, "Studies on the Influence of Knit Structure and Stitch Length on Ring and Compact Yarn Single Jersey Fabric Properties," Textile Research Journal, Vol. 77, No. 8, 2007, pp. 572-582. doi: $10.1177 / 0040517507078023$

[11] S. Gregg and K. Sing, "Adsorption, Specific Surface, Porosity," Moscow, 1970.

[12] M. A. Martinov and K. A. Vylegzhanina, "Rentgenography of Polymers, L." 1972.

[13] G. N. Kukin, A. N. Solovyev and A. I. Koblyakov, "Textile materials science, M.” 1989.

[14] I. M. Muhamedov, "Researching Density of Packaging Structural Elements and Porosity of Fibrous Materials, Thesis," Chemical Technology and Design of Textile Materials and Paper, Tashkent Institute of Textile and Light Industry, Uzbekistan, 1972. 